\title{
Juan Pedro Laporte (1945-2010)
}

\section{Bárbara Arroyo}

\section{OpenEdition}

\section{Journals}

\section{Edición electrónica}

URL: https://journals.openedition.org/jsa/11592

DOI: 10.4000/jsa.11592

ISSN: $1957-7842$

\section{Editor}

Société des américanistes

\section{Edición impresa}

Fecha de publicación: 5 diciembre 2010

Paginación: 293-296

ISSN: 0037-9174

\section{Referencia electrónica}

Bárbara Arroyo, «Juan Pedro Laporte (1945-2010)», Journal de la Société des américanistes [En línea], 96-2 | 2010, Publicado el 22 julio 2010, consultado el 04 septiembre 2022. URL: http:// journals.openedition.org/jsa/11592 ; DOI: https://doi.org/10.4000/jsa.11592 
Juan Pedro LAPORTE (1945-2010)

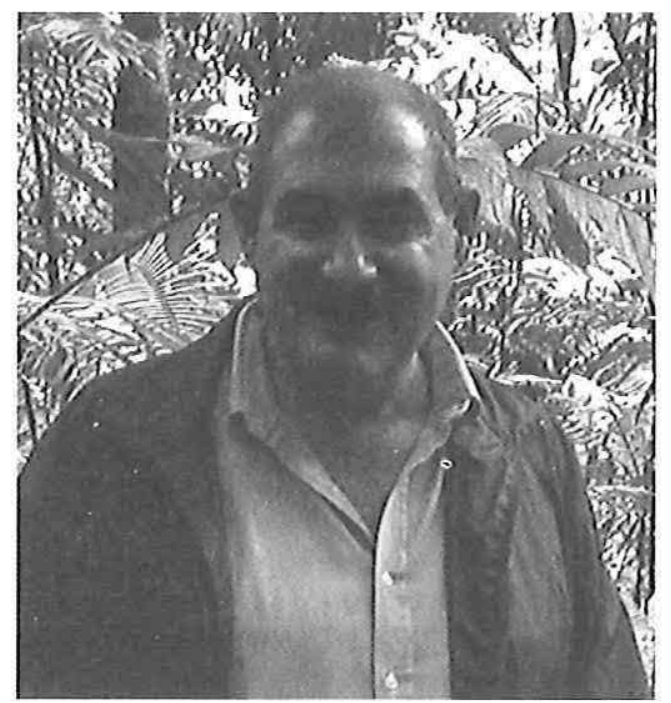

Juan Pedro Laporte nació el 7 de agosto de 1945 y falleció el 22 de enero del 2010. Desde temprana edad tuvo interés en la arqueología por lo que desde la escuela secundaria, se vinculó con el proyecto Tikal, el Museo Nacional de Arqueología y el sitio Kaminaljuyu. A los 19 años inició sus estudios de arqueología en la Universidad de Arizona en Tucson (1964-1965) para trasladarse más tarde a México a continuar su licenciatura y maestría en arqueología en la Escuela Nacional de Antropología e Historia de México (donde terminó su maestría en 1971). Entre 1972 y 1976 realizó estudios de doctorado en arqueología en la Universidad Nacional Autónoma de México. Al año siguiente, en 1977, se incorporó a la Universidad de San Carlos de Guatemala. Su tesis doctoral titulada, Alternativas del Clásico Temprano en la relación TikalTeotihuacan: grupo 6C-XVI, Tikal, Petén, Guatemala, la presentó en 1989. Entre 1967 y 1976 fue investigador y asistente del Departamento de Antropología Física, la Ceramoteca y Máquinas Electrónicas del Museo Nacional de Antropología de México. En esa misma época también fue investigador del Instituto de Investigaciones Antropológicas de la Universidad Nacional Autónoma de México (UNAM).

A partir del terremoto que devastó Guatemala en 1976, Juan Pedro regresó a Guatemala para convertirse en catedrático y coordinador del área de Arqueología de la Escuela de Historia de la Universidad de San Carlos de Guatemala (USAC). Desde 1987 hasta la fecha de su fallecimiento fue encargado de prácticas 
de campo del área de arqueología de la USAC. Ésta fue una magnífica oportunidad para muchos arqueólogos de formarse en el campo con un gran maestro dentro del Proyecto Atlas Arqueológico de Guatemala, con base en Dolores, Petén. Estas prácticas también fueron ofrecidas a estudiantes de la carrera de arqueología de la Universidad del Valle de Guatemala. Además, a partir de estas prácticas, algunos estudiantes persiguieron investigaciones para sus trabajos de tesis de graduación. Juan Pedro fue asesor de 35 tesis de la USAC y 4 del Centro Universitario de Petén.

Durante su formación académica en México, trabajó en varios proyectos, entre los que destaca el importante sitio Formativo de Tlatilco, donde Juan Pedro escribió su tesis de maestría sobre las figurillas del sitio. También realizó investigaciones en Michoacán, Chichen Itzá y Dainzú. En 1974 continuó sus trabajos de campo en Guatemala investigando el sitio Uaxactún y, entre 1974-1976, en Antigua Guatemala así como el departamento de Izabal. Fue en este lugar donde dirigió investigaciones en varios sitios alrededor del Lago de Izabal y de donde asesoró las primeras tesis de licenciatura del área de arqueología de la Escuela de Historia de la USAC. Además, realizó recorridos en la Sierra Santa Cruz y en el valle del Polochic, lugar que fue importante también en investigaciones etnohistóricas de su autoría, a manera de obtener una visión global de las sociedades que habitaron la zona.

Entre 1979 y 1984 tuvo bajo su cargo la excavación y restauración del Complejo Mundo Perdido en Tikal, dentro del Parque Nacional Tikal. Aquí supervisó las excavaciones y restauración de las impresionantes estructuras de este complejo; entre 1982 y 1984 dirigió investigaciones en áreas habitacionales del mismo complejo. En el año 1984, realizó excavaciones en los Grupos A \& B de Uaxactún, Petén, explorando antiguas estructuras así como revisando exploraciones anteriores de la Institución Carnegie de Washington.

A partir de 1985 y hasta la fecha, dirigió y coordinó el Proyecto Atlas Arqueológico de Guatemala. Este proyecto realizó amplios recorridos y levantamientos topográficos de sitios en el sureste del departamento de Petén, que poco a poco se fue extendiendo al norte, centro y oeste del mismo. Su metodología de poca intrusión, favoreció la realización de amplios mapas, además de las excavaciones puntuales en importantes centros como Ixtutz, Ixtonton, Sacul, El Chal, Machaquilá, Ixkun, Pueblito, La Rejoya, Itzimte y Laguna Perdida entre otros muchos. Como parte de sus grandes esfuerzos a la arqueologia de la zona fue la creación del Museo Regional del Sureste de Petén en el pueblo de Dolores, en el Departamento de Petén el cual se inauguró en el año 2005. Juan Pedro siempre tuvo la puerta de su casa y laboratorio en Dolores abierta a los visitantes. Su casa en Dolores fue la base del Proyecto Atlas Arqueológico, y lugar de visita de muchos investigadores de la zona maya.

Juan Pedro fue uno de los fundadores de los Simposios de Investigaciones Arqueológicas en Guatemala donde también fue responsable de las ediciones de 
las memorias. A la fecha el simposio se encuentra en su vigésimo cuarta edición y hasta el año pasado, Juan Pedro fue parte de la comisión organizadora y el editor/coordinador de las memorias. Otro importante proyecto que tuvo a su cargo fue el haber digitalizado los simposios hasta el número 20 y subirlos a la red. Ellos pueden consultarse en la dirección de Asociación Tikal [www. asociaciontikal.com].

Juan Pedro produjo una amplia serie de artículos y libros que fueron publicados en Guatemala, Estados Unidos y Europa. También realizó investigaciones de tipo bibliográfico, siendo una de sus principales obras la Bibliografía de la arqueología guatemalteca (1981), donde invirtió años para identificar e inventariar una gran cantidad de obras publicadas en diversas partes del mundo relacionadas con la arqueología maya. Llevó un sistemático control de las tesis de graduación de licenciados en arqueología tanto de la Universidad de San Carlos de Guatemala como de la Universidad del Valle. Fue un firme creyente en compartir y divulgar al máximo la información arqueológica por lo que digitalizó los reportes del Atlas Arqueológico y sacando fondos de su presupuesto personal, patrocinó el sitio en la red que incluye los mismos [http://www. atlasarqueologico.com/]. Además, como se mencionó antes, trabajó intensamente en la digitalización de las memorias de los Simposios de Investigaciones Arqueológicas en Guatemala. Dejó varios trabajos inéditos, algunos de los cuales estaban pensados para leerse virtualmente ya que él consideraba que esto era el futuro de los libros. Tuvo grandes colaboraciones con colegas nacionales y extranjeros, con quién también publicó importantes trabajos en libros y revistas internacionales.

Como profesional también participó en múltiples congresos internacionales alrededor de América, Europa y Asia, representando a Guatemala ante el mundo. Tuvo muchas colaboraciones internacionales, en particular con investigadores del CEMCA de la Embajada de Francia, de la UNAM de México, de la Universidad Complutense de Madrid, investigadores norteamericanos de varias universidades, y más recientemente, de la Universidad de Ibaraki en Japón.

Su extensa experiencia profesional promovió su participación como asesor en el Consejo Nacional para la Protección de Antigua, vocal del Consejo Técnico de Arqueología del Instituto de Antropología e Historia de Guatemala, vocal de la Junta Directiva de la Asociación Tikal, además de representar al Ministerio de Cultura y Deportes en expertajes sobre materiales arqueológicos localizados en el extranjero. También fue convocado para opinar sobre exposiciones internacionales relacionadas a la civilización maya tanto en Estados Unidos como Europa. Fue miembro de consejos editoriales de la revista Latin American Antiquity y, más recientemente, de las revistas Mayab y Revista Española de Antropología Americana.

Entre algunas de sus obras se encuentran La organización territorial y política en el mundo maya clásico: el caso del sureste y centro-oeste de Petén, Guatemala, 
junto a Héctor Mejia (2005). Tikal, city of wealth and power: a walking guide to the ruins of Tikal, junto a Peter Harrison y un sin número de artículos en libros y revistas profesionales.

Fue editor de la serie Utzíb y Reportes de Utzíb de la Asociación Tikal. A Juan Pedro se le ha referido como la «Piedra angular de la arqueología guatemalteca » (Redacción DGCA 2010), «Pilar de la arqueología nacional » (León 2010) y también como quien dedicó su vida a revivir nuestro pasado (Palma Murga 2009). Su ejemplo de profesionalismo, dedicación y seriedad con un toque personal especial, ha quedado en todos aquellos que tuvimos la suerte de trabajar de cerca con él.

\section{REFERENCIAS}

LEÓN Lucía

2010 "Muere pilar de la arqueología nacional», Siglo XXI, 23 de enero, Guatemala.

Palma Murga Gustavo

2010 "Una vida dedicada a revivir nuestro pasado », Diario de Centroamérica, lunes 8 de febrero, Guatemala.

Bárbara Arroyo

Universidad San Carlos de Guatemala 